\title{
Submerged membrane coagulation hybrid system as pretreatment to organic matter removal from seawater
}

\author{
Sanghyun Jeong, Tien Vinh Nguyen, Saravanamuthu Vigneswaran* \\ Faculty of Engineering and IT, University of Technology, Sydney (UTS), PO Box 123, \\ Broadway, NSW 2007 Australia \\ email:, sanghyun.jeong@student.uts.edu.au,tien.nguyen@eng.uts.edu.au, \\ s.vigneswaran@uts.uts.au \\ * Corresponding author: Tel. +61-2-9514-2614; Fax. +61-2- 9514-2633; email: \\ s.vigneswaran@uts.uts.au
}

\begin{abstract}
In this study, a commonly used ferric chloride was utilised as coagulant for removing organic compounds from seawater. More than 57\% of dissolved organic carbon (DOC) was removed at optimum dosage of $3 \mathrm{mg} \mathrm{Fe} / \mathrm{L}$. The coagulation by $\mathrm{FeCl}_{3}$ at optimum dosage could remove a majority (95\%) of hydrophobic compounds. The results from Liquid Chromatography - Organic Carbon Detector (LC-OCD) showed that only less than 0.02 $\mathrm{mg} / \mathrm{L}$ of hydrophobic compounds was found after coagulation. In addition, the modified fouling index decreased considerably from $15848 \mathrm{~s} / \mathrm{L}^{2}$ with raw seawater to $3025 \mathrm{~s} / \mathrm{L}^{2}$ with seawater after coagulation. In-line coagulation coupled with submerged membrane system (ICSMS) was also trialled. It is observed that critical flux was increased from $20 \mathrm{~L} / \mathrm{m}^{2} \cdot \mathrm{h}$ in the conventional submerged membrane system to $55 \mathrm{~L} / \mathrm{m}^{2} . \mathrm{h}$ in ICSMS. The ICSMS could remain the high DOC removal efficiency (more than 70\%) at filtration rate of $20 \mathrm{~L} / \mathrm{m}^{2} \cdot \mathrm{h}$ when keeping the development of trans-membrane pressure (TMP) was significant lower than that of conventional submerged membrane system.
\end{abstract}

Keywords: Desalination; ferric chloride; in-line coagulation, organic matter; seawater

\section{Introduction}

The growth in a number of countries suffering from a shortage of natural fresh water has been exponential over the last decade and is expected to continue as per capita water requirements increase, populations multiply and enhanced living standards coupled with the expansion of industrial and agricultural activities. Nowadays, many countries choose desalination technologies for the purpose of meeting their fresh water requirements. It is estimated that over 75 million people worldwide cover insufficient water from desalination plant (Khawajia et al. 2008).

Treatment of seawater using membrane technology, especially by reverse osmosis (RO) is becoming popular. However, membrane fouling by natural organic matter (NOM) is a very common problem (Prihasto et al. 2009). Membrane fouling reduce the quality and quantity of producing water, lead to higher operating costs such as demanding energy, cleaning for maintenances as well as damage the membrane itself (Sheikholeslami and Bright 2002).

Pretreatment of feed water is effective and necessary method for reducing membrane fouling. To ensure the expected quality of feed water to RO process, an increasing number of researchers nowadays considering the use of membrane based pretreatment coupled with 
conventional pretreatment which includes coagulation/flocculation (Ma et al. 2007; Shon et al. 2009; Choi et al. 2009).

Coagulation is one of the pretreatment methods that can improve the permeate flux of membrane while removing particles and colloids. Coagulation can achieves three objectives: (a) eliminating the penetration of colloidal particles into the membrane pores, (b) increasing the critical flux, and (c) modifying the characteristics of deposit (Visvanathan and Ben Aim 1989). Some coagulation studies shown the importance and the superiority of $\mathrm{FeCl}_{3}$ due to the trivalent ferric ions $\left(\mathrm{Fe}^{+3}\right)$ readily undergo hydrolysis, complexation/polymerisation and precipitation in aqueous solution (Visvanathan and Ben Aim 1989; Chapman et al. 2002). Brehant et al. (2002) showed that an in-line injection of $1 \mathrm{mg} / \mathrm{L}$ of $\mathrm{FeCl}_{3}$ with UF could help in controlling fouling by reducing the silt density index of surface seawater from $13-25$ to below 1 .

In this study, a commonly used ferric chloride was used as coagulant for removing organic compounds from seawater. In-line coagulation coupled with micro-filtration process was also experimentally investigated as pretreatment for RO.

\section{Material and methods}

\subsection{Materials}

\subsubsection{Seawater}

This study was conducted with seawater drawn from Chowder Bay, Sydney, Australia. Seawater was pumped from $1 \mathrm{~m}$ below the sea surface level and filtered using a centrifuge filtration system to remove the large particles. The characteristics of the seawater are presented in Table 1.

The values of $\mathrm{pH}$, turbidity (NTU), conductivity $(\mathrm{mS} / \mathrm{cm})$ and salinity $(\mathrm{g} / \mathrm{L})$ were measured by a $\mathrm{pH}$ meter (HANNA, HI902), a turbidity meter (HACH, 2100P) and a conductivity and salinity meter (WTW, LF330) respectively at the room temperature $\left(25 \pm 1.0^{\circ} \mathrm{C}\right)$. The analysis of total suspended solids (TSS) was carried out in the laboratory according to the procedure of Standard Methods (APHA, 1995).

Table 1 Characteristics of seawater used in this study

\begin{tabular}{ll}
\hline Analysis category & Measurement value \\
\hline $\mathrm{pH}$ & 7.98 \\
Conductivity (ms/cm) & 51.8 \\
$\mathrm{UV}_{254}\left(\mathrm{~cm}^{-1}\right)$ & 0.026 \\
$\mathrm{UF}-\mathrm{MFI}\left(\mathrm{s} / \mathrm{L}^{2}\right)$ & 15848 \\
Salinity (g/L) & 35.5 \\
TSS $(\mathrm{mg} / \mathrm{L})$ & 3.6 \\
Turbidity (NTU) & 0.41 \\
DOC (mg/L) & 1.29 \\
\hline
\end{tabular}

\subsubsection{Membrane}

The membrane used in this study was hollow fibre micro-filtration (MF). Hollow fibre MF (Cleanfil $^{\circledR}-\mathrm{S}$, Polysulfone, Polyethersulfone, PVDF of $0.1 \mu \mathrm{m}$, Kolon membrane) was vertically submerged directly into a reactor. The U-type membrane length was $48.5 \mathrm{~cm}$ with 
an outer diameter of $2 \mathrm{~mm}$. The combined surface area of the hollow fiber membrane was $0.1 \mathrm{~m}^{2}$.

\subsection{Coagulation}

\subsubsection{Determination of optimum dose}

$\mathrm{FeCl}_{3}$ was used as coagulant and its optimum dose was determined by standard jar tests. The seawater was placed in $1 \mathrm{~L}$ beakers and predetermined amounts of coagulant were added in. The samples were then stirred rapidly for 2 minutes at $120 \mathrm{rpm}$, followed by 20 minutes of slow mixing at $30 \mathrm{rpm}$, and 30 minutes of settling. The supernatant was taken and analysed for DOC to determine the effects of the coagulant in the removal of organic matter.

\subsubsection{Modified fouling index (MFI)}

The modified fouling index (MFI) was established by Schipper and Verdouw (1980) to evaluate membrane fouling mechanism. The schematic diagram of MFI experimental set-up is shown in Fig. 1. MFI is determined at standard reference values of $207 \pm 3 \mathrm{kPa}$, a feed water temperature of $20^{\circ} \mathrm{C}$ and ultrafilter (UF) with a $47 \mathrm{~mm}$ diameter and molecular cut-off is 17.5 $\mathrm{kDa}$. The ultrafilter - modified fouling index (UF-MFI) can be indicated whether coagulation was effective to reduce the fouling potential of membrane.

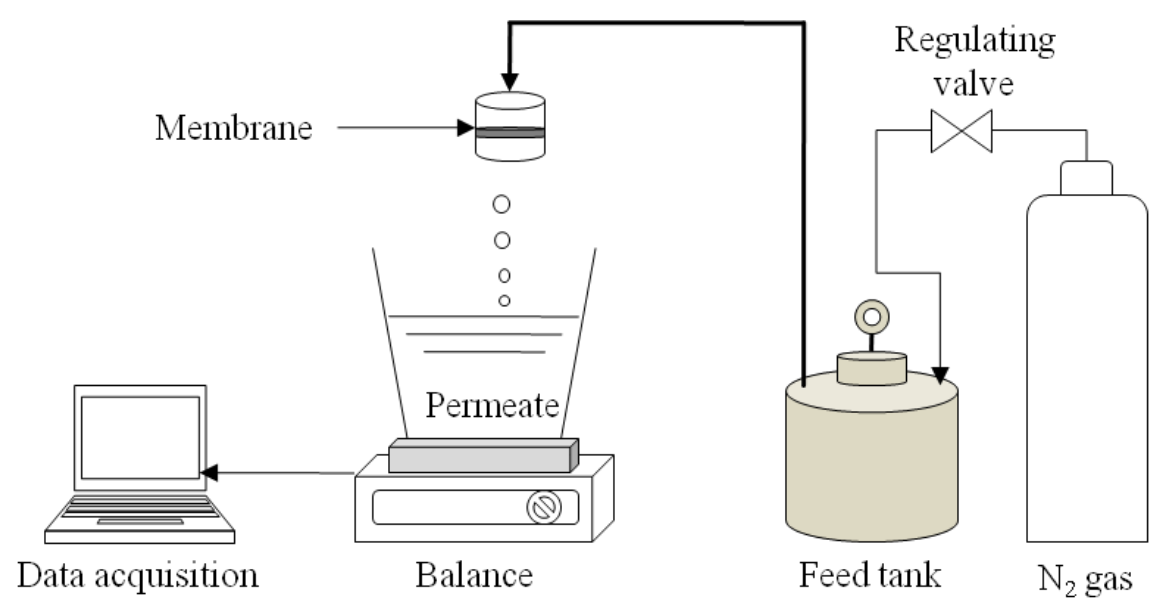

Fig. 1 UF-MFI experimental set-up

\subsection{Hollow fibre micro-filtration coupled with in-line coagulation}

The schematic diagram of the experimental hollow fibre micro-filtration (MF) set-up used in this study is shown in Fig. 2. In-line coagulation with different doses of $\mathrm{FeCl}_{3}$ and filtration experiments was carried out using hollow fibre MF in column type reactor. The effective volume of reactor was $6 \mathrm{~L}$ and aeration rate that injected from the bottom of reactor was 1 $\mathrm{L} / \mathrm{min}$ at pre-determined flow rate. Permeate was pumped out using a peristaltic pump at constant flux. After each experiment, membrane cleaning was carried out with chemicals. The membrane was placed into $0.2 \% \mathrm{NaOH}$ and $0.2 \% \mathrm{NaOCl}$ (total volume was $2 \mathrm{~L}$ ) solution using horizontal shaker at $60 \mathrm{rpm}$ for $3 \mathrm{~h}$. The data of permeate flow rate was 
recorded automatically. The trans-membrane pressure (TMP) was recorded using data logger in every 5 mins.

Continuous micro-filtration experiments were conducted without stoppage and cleaning. For TMP measurements in this study, the permeate flow velocity was kept approximately constant at $33.3 \mathrm{~mL} / \mathrm{min}$ (corresponding to a constant flux of $20 \mathrm{~L} / \mathrm{m}^{2} \cdot \mathrm{h}$ ). The temperature was maintained at $25^{0} \mathrm{C}$.

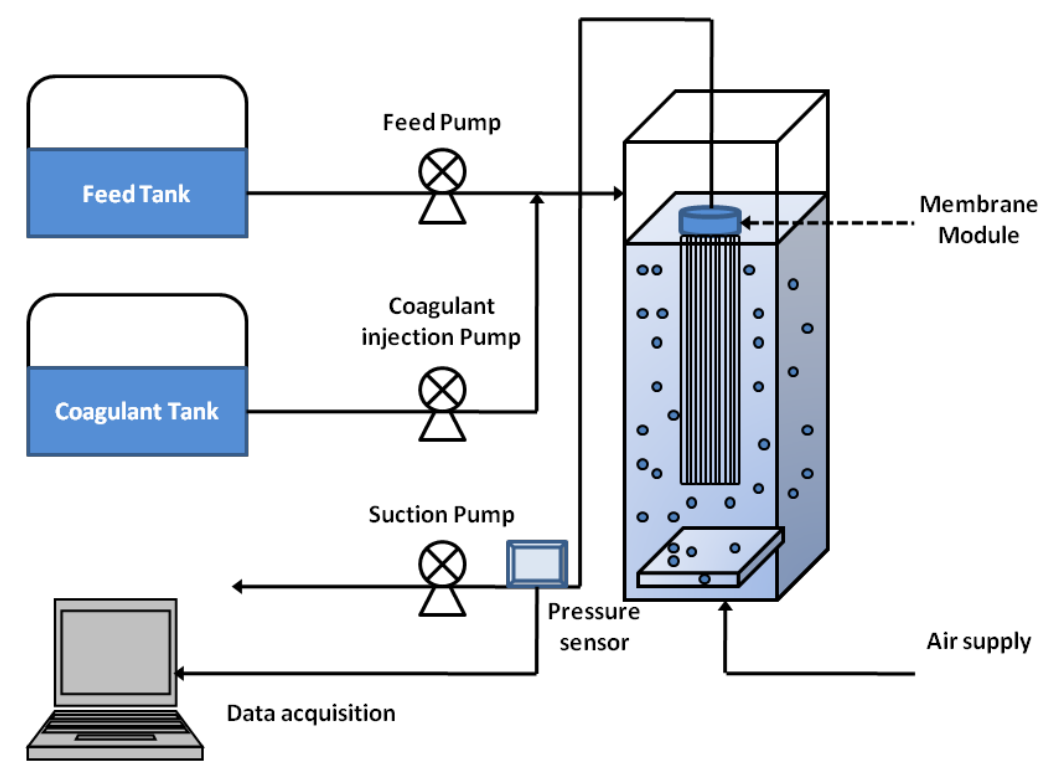

Fig. 2 Schematic diagram of hollow fibre submerged MF membrane coupled with in-line coagulation

\subsection{Analytical measurement by liquid chromatography with organic carbon detector}

DOC was measured after filtering samples through $0.45 \mu \mathrm{m}$ filter and organic fractions were measured by DOC-LABOR Liquid Chromatography - Organic Carbon Detector (LC-OCD). This system uses size-exclusion chromatography to separate classes of dissolved organic materials (organic acids, bases and neutral species) before measuring by a catalysed UV oxidation. LC-OCD was measured to identify the different classes of organic compounds present in seawater to cause organic fouling. It gives the both qualitative and quantitative information of the organic matter present in seawater before and after treatment. LC-OCD can be employed to acquire the organic matter (OM) information in details.

\section{Results and discussion}

\subsection{Jar test experiments}

Table 2 presents the variation of turbidity and $\mathrm{pH}$ as functions of coagulant concentrations. $\mathrm{pH}$ of seawater after coagulation slightly decreased when the dose of $\mathrm{FeCl}_{3}$ increase to 4.0 $\mathrm{mg} / \mathrm{L}$. Surprisingly, the turbidity of seawater increased after coagulation and this phenomenon was similar to the one observed by Chinu et al (2010). Experiment from Jar test also shows that there was no floc if the concentration of coagulant was below $1.0 \mathrm{mg} / \mathrm{L}$ (in terms of $\mathrm{Fe}^{+3}$ ). 
Table 2 The turbidity and the $\mathrm{pH}$ after coagulation

\begin{tabular}{ccccccc}
\hline & Raw & \multicolumn{5}{c}{$\mathrm{Fe}^{+3}(\mathrm{mg} / \mathrm{L})$} \\
\cline { 3 - 7 } & Seawater & 0.5 & 1.0 & 2.0 & 3.0 & 4.0 \\
\hline $\mathrm{pH}$ & 7.98 & 7.53 & 7.41 & 7.25 & 7.22 & 7.16 \\
Turbidity (NTU) & 0.41 & 1.26 & 1.83 & 1.33 & 1.43 & 1.65 \\
\hline
\end{tabular}

The addition of ferric chloride may generate ferric hydroxide and ferric oxide which caused to the increase of turbidity after coagulation. The increase of turbidity was noted for all $\mathrm{FeCl}_{3}$ doses (Table 2). Thus, optimum dose of $\mathrm{FeCl}_{3}$ cannot be determined in terms of turbidity.

The analyses of organic fractions of seawater by LC-OCD showed that the DOC of seawater used in this study was $1.29 \mathrm{mg} / \mathrm{L}$ in which $33 \%$ of total DOC was hydrophobic. The humic substances with molecular weight about $1000 \mathrm{Da}$ account more than half of hydrophilic part (51\% of hydrophilic). The percentage of bio-polymers ( $\mathrm{MW}>20,000 \mathrm{Da}$ ), building block (MW $\approx 300-500 \mathrm{Da}$ ), and low molecular weight of neutrals (MW < $350 \mathrm{Da}$ ) were 15\%, 23\%, and $11 \%$ respectively.

Table 3 presents the variation of DOC removal efficiency as a function of concentrations of $\mathrm{Fe}^{+3}$. It can be seen that the more than $57 \%$ of DOC was removed at the optimum dosage of $3.0 \mathrm{mg} \mathrm{Fe} / \mathrm{L}$. At lower doses, the DOC removal efficiencies were below 50\%. Further increase of $\mathrm{Fe}^{+3}$ concentration to $4.0 \mathrm{mg} / \mathrm{L}$, the DOC removal efficiency decreased. This may be due to the restabilisation of the colloidal particles.

Table 3 Removal efficiency of different fractions of organic matter in seawater by coagulation with $\mathrm{FeCl}_{3}$

\begin{tabular}{llllllll}
\hline $\begin{array}{l}\mathrm{Fe}^{+3} \text { conc. } \\
(\mathrm{mg} / \mathrm{L})\end{array}$ & DOC & $\begin{array}{l}\text { Hydro- } \\
\text { phobic }\end{array}$ & $\begin{array}{l}\text { Hydro- } \\
\text { philic }\end{array}$ & $\begin{array}{l}\text { Bio- } \\
\text { polymer }\end{array}$ & Humic & $\begin{array}{l}\text { Building } \\
\text { blocks }\end{array}$ & Neutrals \\
\hline 0.5 & $(\%)$ & $(\%)$ & $(\%)$ & $(\%)$ & $(\%)$ & $(\%)$ & $(\%)$ \\
1.0 & 50 & 98 & 28 & 38 & 16 & 15 & 100 \\
2.0 & 49 & 98 & 24 & 46 & 11 & 20 & 67 \\
3.0 & 47 & 74 & 33 & 54 & 16 & 30 & 89 \\
4.0 & 57 & 95 & 37 & 69 & 18 & 30 & 100 \\
\hline
\end{tabular}

Detailed analyses of organic fractions after coagulation shows that coagulation by $\mathrm{FeCl}_{3}$ could remove a majority of hydrophobic fraction. However coagulation was not effective in removing hydrophilic, except neutrals part with molecular weight below $350 \mathrm{Da}$ and biopolymer with large molecular weight (MW more than 20,000 Da) (Table 3). This trend was similar to results reported by Shon et al. (2005).

The reduction of the fouling potential of seawater before and after coagulation was also studied using modified fouling index with ultrafilter membrane of $17.5 \mathrm{kDa}$ (UF-MFI). The results showed that the coagulation led to significantly decrease of UF-MFI (Table 4). The 
UF-MFI reduced about 5 times from $15848 \mathrm{~s} / \mathrm{L}^{2}$ to less than $3209 \mathrm{~s} / \mathrm{L}^{2}$ at all of the studied doses.

Table 4 The ultrafilter-modified fouling index of seawater before and after coagulation with different $\mathrm{FeCl}_{3}$ doses

\begin{tabular}{lccccc}
\hline & Raw & \multicolumn{5}{c}{$\mathrm{Fe}^{+3}(\mathrm{mg} / \mathrm{L})$} \\
\cline { 3 - 6 } & seawater & 1.0 & 2.0 & 3.0 & 4.0 \\
\hline UF-MFI $\left(\mathrm{s} / \mathrm{L}^{2}\right)$ & 15848 & 3209 & 2238 & 3025 & 2771 \\
\hline
\end{tabular}

\subsection{In line coagulation coupled with micro-filtration}

\subsubsection{Critical flux}

In this experiment, critical flux was measured quantitatively by a "flux stepping" method. The membrane reactor was operated at a fixed flux for around 60 minutes and the TMP was monitored simultaneously. The flux was then increased and operated at a constant flux for another 60 minutes and so on. As the flux was increased gradually, the critical flux condition was detected where TMP no longer remained steady but increased with time. The maximum flux which showed no increase in TMP was taken as the critical flux.

The critical flux of micro-filtration system with seawater (without any coagulation) was only $20 \mathrm{~L} / \mathrm{m}^{2}$.h (Fig. 3a). The coupling of in-line coagulation with hollow fibre submerged MF membrane reactor led to increase of critical flux and the increase of critical flux was related with the increase of coagulation doses (Fig. 3b, 3c). The critical flux increased to 35 and 55 $\mathrm{L} / \mathrm{m}^{2} . \mathrm{h}$ when $0.5 \mathrm{mg} / \mathrm{L}$ and $3.0 \mathrm{mg} / \mathrm{L}$ of $\mathrm{Fe}^{+3}$ were used as coagulant. 


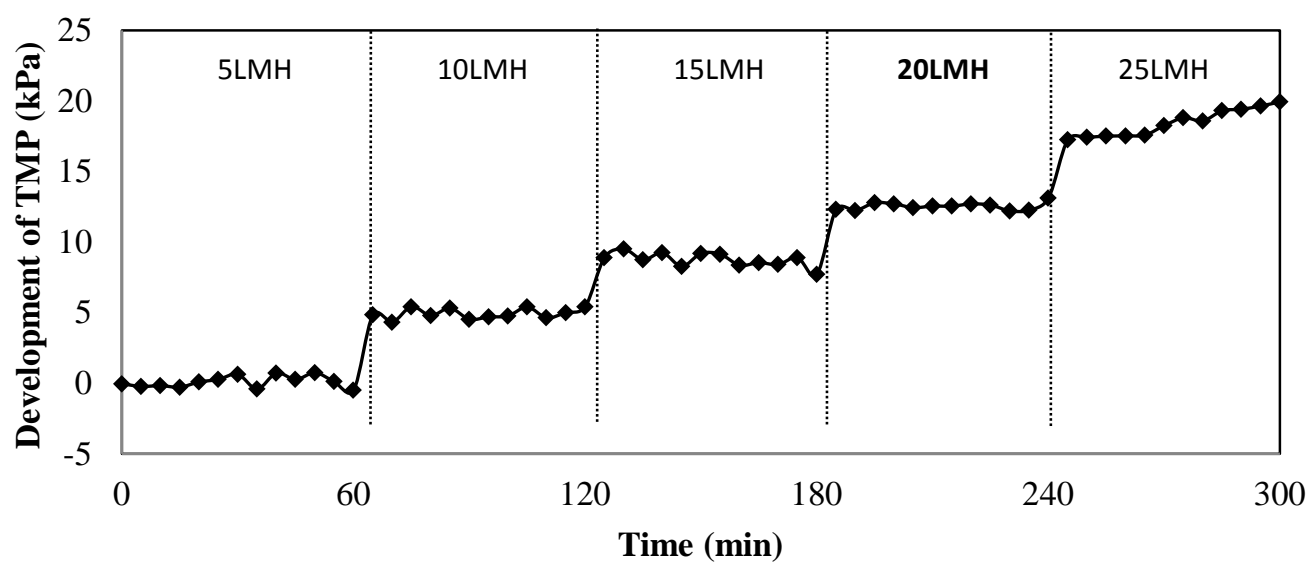

(a) $\mathrm{Fe}^{+3}$ doses: $0 \mathrm{mg} / \mathrm{L}$ (Without coagulant)

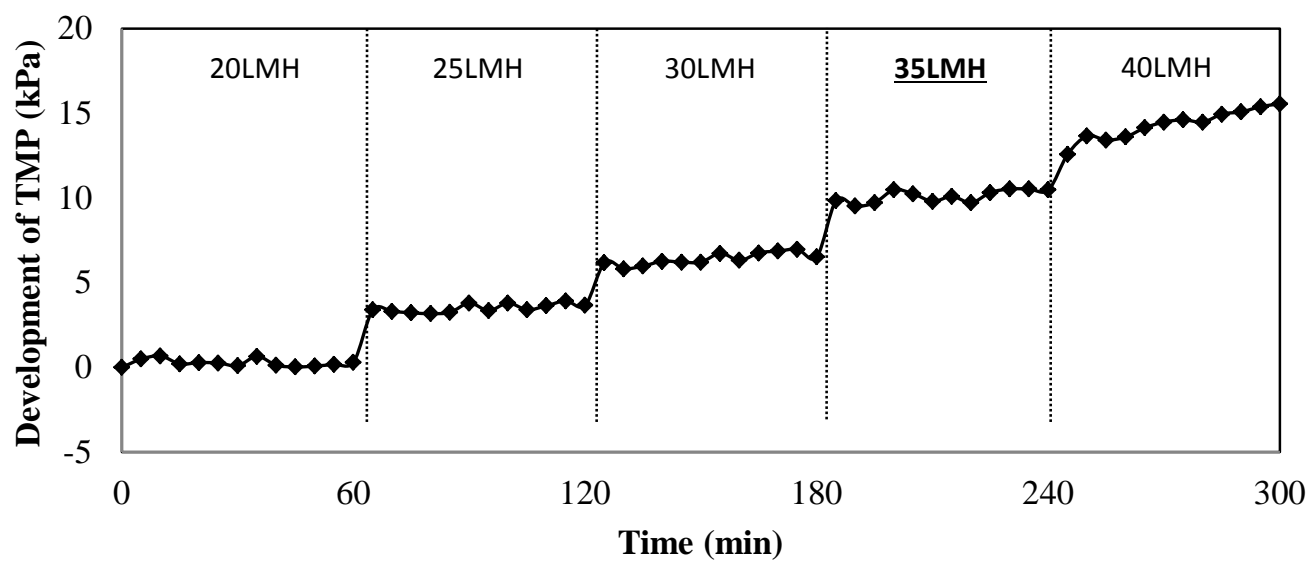

(b) $\mathrm{Fe}^{+3}$ doses: 0.5mg/L

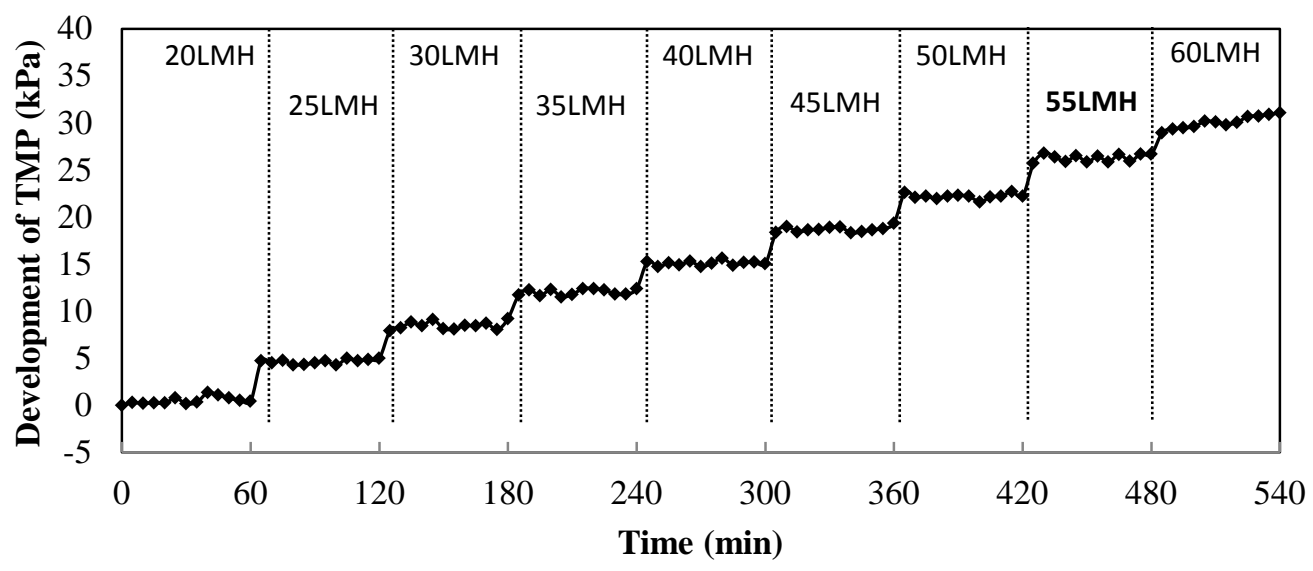

(c) $\mathrm{Fe}^{+3}$ doses: 3.0mg/L

Fig. 3 Variation of TMP values $\left(\mathrm{LMH}=\mathrm{L} / \mathrm{m}^{2} \cdot \mathrm{h}\right)$ 


\subsubsection{Organic removal}

It was observed that by coupling in-line coagulation with MF, more than $57 \%$ of hydrophilic compounds could be removed (Table 5). This value was about $20 \%$ higher than that of coagulation alone. As a result, the DOC removal of in-line coagulation coupled with submerged membrane system was also much higher than that of coagulation alone. On the other hand, when seawater was filtrated by MF alone, DOC removal efficiency was only $17 \%$. The capacity of removal efficiency of hydrophilic compounds could improve nearly 10 times when in-line coagulation was coupled with MF (Table 5).

Table 5 Fraction of organic matter after MF filtration coupled with coagulation for $24 \mathrm{~h}$ (filtration flux $20 \mathrm{~L} / \mathrm{m}^{2} . \mathrm{h}, \mathrm{Fe}^{+3}$ doses: $3.0 \mathrm{mg} / \mathrm{L}$ )

\begin{tabular}{|c|c|c|c|c|c|c|c|}
\hline Feed water & $\begin{array}{l}\text { DOC } \\
(\%)\end{array}$ & $\begin{array}{c}\text { Hydro- } \\
\text { phobic } \\
(\%)\end{array}$ & $\begin{array}{c}\text { Hydro- } \\
\text { philic } \\
(\%)\end{array}$ & $\begin{array}{c}\text { Bio- } \\
\text { polymer } \\
(\%)\end{array}$ & $\begin{array}{c}\text { Humic } \\
\text { (\%) }\end{array}$ & $\begin{array}{c}\text { Building } \\
\text { blocks } \\
(\%)\end{array}$ & $\begin{array}{c}\text { Neutrals } \\
\text { (\%) }\end{array}$ \\
\hline $\begin{array}{c}\text { Seawater by MF } \\
\text { alone }\end{array}$ & 17 & 27 & 12 & 38 & 0 & 0 & 56 \\
\hline After 2hrs & 70 & 95 & 57 & 62 & 55 & 40 & 100 \\
\hline After 24hrs & 71 & 95 & 58 & 85 & 66 & 20 & 67 \\
\hline
\end{tabular}

The results from both jar test and in-line coagulation also showed that the removal efficiency of hydrophobic compounds was much higher than that of hydrophilic compounds (Tables 3 and 5). In this study, the hydrophobic compounds of experimental seawater only accounted for a third of NOM. Therefore, for seawater containing more hydrophobic NOM, more DOC removal can be achieved by coagulation process.

\subsubsection{Trans-membrane pressure}

The variations of trans-membrane pressure (TMP) of conventional submerged membrane system and in-line coagulation with pre-selected two doses $\left(0.5 \mathrm{mg} \mathrm{Fe}^{+3} / \mathrm{L}\right.$ and $\left.3.0 \mathrm{mg} \mathrm{Fe} / \mathrm{L}\right)$ coupled with membrane system with seawater are presented in Fig. 4. As can be seen from this figure, the TMP of conventional submerged membrane system increased rapidly and reached more than $10 \mathrm{kPa}$ within the first day of operation. The coupling of in-line coagulation with submerged membrane system helped reduce the increase of TMP and at $\mathrm{Fe}^{+3}$ dose of $3.0 \mathrm{mg} / \mathrm{L}$, the development of TMP after 14 days of operation was still lower than that of conventional submerged membrane system after first day of operation. This shows that in-line coagulation helped reducing membrane fouling significantly. 


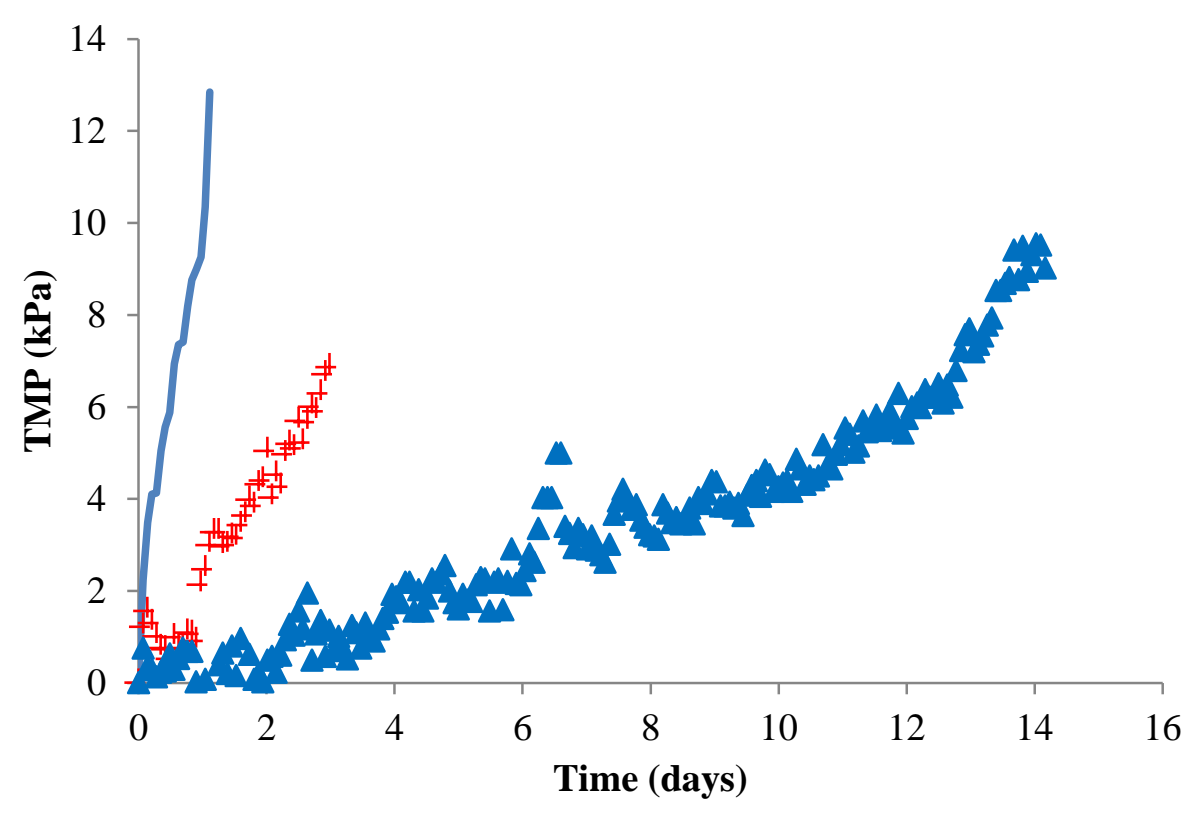

Without coagulation + Coagulation: $\mathrm{Fe}^{+3}=0.5 \mathrm{mg} / \mathrm{L} \quad \boldsymbol{\Delta}$ Coagulation: $\mathrm{Fe}^{+3}=3.0 \mathrm{mg} / \mathrm{L}$

Fig. 4 The development of TMPs of a submerged membrane reactor with and without in-line coagulation (filtration flux $20 \mathrm{~L} / \mathrm{m}^{2} \cdot \mathrm{h}$ )

\section{Conclusion}

The results from this study showed that ferric chloride could remove $57 \%$ of DOC from seawater collected at Chowder Bay, Sydney, Australia. The removal efficiency of hydrophobic compounds by coagulation were much higher than that of hydrophilic compounds removed with $95 \%$ of hydrophobic compounds and $37 \%$ of hydrophilic compounds could be removed at $\mathrm{Fe}^{+3}$ dosage of $3.0 \mathrm{mg} / \mathrm{L}$. The coagulation also could reduce 5 times of UF-MFI in batch mode as well as increase 3 times of the critical flux of submerged membrane system when it was coupled with in-line coagulation. The in-line coagulation coupled with submerged membrane system was found to remove DOC effectively with more than $70 \%$ DOC removal.

\section{Acknowledgments}

This study was supported by National Centre of Excellence in Desalination (Membrane flocculation hybrid system as pre-treatment to brackish and sea water reverse osmosis desalination system).

\section{References}

1. APHA, AWWA, WEF. (1995). Standard Methods for the Examination of Water and Wastewater, $19^{\text {th }}$ ed. American Public Health Association; American Water Works Association and Water Environment Federation, USA

2. Brehant A., Bonnelye V., Perez M. (2002). Comparison of MF/UF pretreatment with conv. filtration prior to RO membranes for surface seawater desalination, Desalination 144, 353-360

3. Chapman H., Vigneswaran S., Ngo H.H., Dyer S., Ben Aim R. (2002). Preflocculation of secondary treated wastewater in enhancing the performance of microfiltration, Desalination 146, 367-372 
4. Chinu K., Johir A.H., Vigneswaran S., Shon H.K., Kandasamy J. (2010). Assessment of pretreatment to microfiltration for desalination in terms of fouling index and molecular weight distribution, Desalination 250, 644-647

5. Choi Y.H., Kweon J.H., Kim D.I., Lee S. (2009). Evaluation of various pretreatment for particle and inorganic fouling control on performance of SWRO, Desalination 247, 137-147

6. Khawajia A.D., Kutubkhanah I.K., Wie J.M. (2008). Advances in seawater desalination technologies, Desalination 221, 47-69

7. Ma W., Zhao Y., Wang L. (2007). The pretreatment with enhanced coagulation and a UF membrane for seawater desalination with reverse osmosis, Desalination 203, 256259

8. Prihasto N., Liu Q.F., Kim S.H. (2009). Pre-treatment strategies for seawater desalination by reverse osmosis system, Desalination 249, 308-316

9. Schippers J.C., Verdouw J. (1980). The Modified Fouling Index. A Method of determining the Fouling Characteristics of Water, Desalination 32, 137-148

10. Sheikholeslami R., Bright J. (2002). Silica and metals removal by pretreatment to prevent fouling of reverse osmosis membranes, Desalination 143, 255-267

11. Shon H.K., Vigneswaran S., Ben Aim R., Ngo H.H., Kim In S., Cho J. (2005). Influence of flocculation and adsorption as pretreatment on the fouling of ultrafiltration and nanofiltration membranes: application with biologically treated sewage effluent, Environmental Science and Technology 39, 3864-3871

12. Shon H.K., Vigneswaran S., Zareie M.H., Ben Aim R., Lee E., Lee J., Cho J., Kim In S. (2009). Physico-chemical pretreatment to seawater reverse osmosis (SWRO): organic characterisation and membrane autopsy, Desalination 236, 282-290

13. Visvanathan C. and Ben Aim R. (1989). Studies on colloidal membrane fouling mechanisms in crossflow, Journal of Membrane Science 45, 3-15 